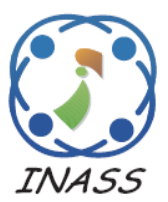

\title{
Concentric Circular Ring Loaded Triple Band Antenna for Wireless Applications
}

\author{
Soma Sekhar Rao Kolusu ${ }^{1 *}$
}

\author{
Ajay Babu Modala ${ }^{1}$ \\ Boddapati Taraka Phani Madhav ${ }^{1}$ \\ Badugu Prudhvi Nadh ${ }^{1}$
}

\begin{abstract}
The article presents the design of the concentric circular ring antenna is designed for wireless application like WLAN, Bluetooth, ISM and WiMAX applications. The antenna provides the triple band characteristics frequencies ranging from2.2-3.6 GHz with impedance bandwidth of $48 \%$ at the first band,4.3-4.6 GHz with impedance bandwidth of $9 \%$ at second operating frequency and third band ranging from 5.2-5.7 $\mathrm{GHz}$ with impedance bandwidth of $10 \%$ is observed. The antenna provides the bidirectional and omni directional radiation patterns. The antenna provides the peak gain of 2.05 at $2.9 \mathrm{GHz}, 3.9 \mathrm{dBi}$ at $4.3 \mathrm{GHz}$ and $3.5 \mathrm{dBi}$ at $5.4 \mathrm{GHz}$ at three resonating frequency. The radiation efficiency at the three resonating bands is $96 \%$ at $2.05 \mathrm{GHz}, 93 \%$ at $4.3 \mathrm{GHz}$ and $86 \%$ at $5.4 \mathrm{GHz}$. The frequency reconfigurable properties are observed.
\end{abstract}

Keywords: Circular rings, UWB band, CPW feed.

\section{Introduction}

In the previous few years, UWB (Ultra-Wide Band) technology working with frequency ranging from band 3.1-10.6 GHz has fascinating attention because of its benefits. Example, low power requirement, large channel capacity in this way high information rate, less affectability to the multipath impact resistance to jamming etc. Owing to these preferences the UWB innovation has been received broadly in numerous applications, for example, short range indoor communications, cognitive radio detecting and imaging frameworks, radar target localisation and characterisation, car applications etc. Recently a few UWB antennas with reconfigurable band rejection utilizing dynamic exchanging components, for example, PIN diodes, varactor diodes, radio frequency micro-electromechanical system (MEMS). As field have been accounted for a large portion of these radio wires are equipped for dismissing or tuning a solitary band just (WiMAX or WLAN) respectively [1]. Among these antennas printed monopole antennas plays a critical job because of their attractive highlights of a basic structure, a low profile and sensibly decent execution. Particularly studies on the circular ring monopole antenna have been conducted [2]. Reconfigurable and multiband antennas have gained importance in RF-systems and software defined radio sensing systems. These reconfigurable antennas reduce the bulk hardware components and provide multifunctionality with compact structure. The usage of Pin diodes is commercially available and easy to fabricate the antenna when compared to MEMS switches integration of switches is very complicated when compared to Pin diodes.

In the previous literature to achieve the multiband operation in microstrip antennas they use several strips and stacked structures for creating different currents paths. In the convectional techniques increases the dimensions of antenna and creating structure complexity. Even though the use of the conventional LC-Loading techniques has also used to achieve the multiband frequencies, but he 
complexity of design increases. In the proposed article BAR-64-02V Pin diodes are used to multifrequency applications. Because of quick development of wireless communication in everyday life communication system requires microstrip antenna, which is minimized, adaptable, light weight, ease and simple to coordinate with little size and handheld convenient wireless devices [3]. To stay away from obstruction of UWB systems with these signals a band stop channel is required. A different channel along with UWB antenna will expand general size of antenna. A reduced stop band system that can be embedded with antenna without expanding the size is required. In this setting a few specialists have revealed their work to make the notched-band characteristics [4]. UWB monopole antenna with projected structure have been accounted for these antennas are not suitable for integration with a printed circuit board as a result of non-planar sort configuration [5]. Circular polarization is a standout amongst the most engaging polarization conspires due to having high immunization to multipath impedances, robustness to polarization mismatches between the transmitter and receiver and better transmission qualities in adverse weather conditions. It is subsequently broadly utilized in different applications, for example, RFID, radar, WLAN, worldwide situating and satellite systems [6].

The main aim of this work is to design the antenna with reconfigurable property and switch to different frequency applications. To attain the reconfigurable property antennas uses the active switching elements such as diodes, RF-MEMS, GaAS-field-effect Transistors and optically tuned switches are used. Out of this BAR-64-02V Pin diodes are used in this paper to check the reconfigurable functionality. As the circular polarization antenna can offer increasingly dependable accepting affectability and has better behaviour during atmospheric propagation. It is exceptionally wanted in mobile wireless communication [8]. In traditional reconfigurable antennas, the bias lines are two overlap and arrival way should be made also to trigger dynamic switch $[9,10]$. In this letter we expand the reconfiguration principle of a double band antenna configuration to accomplish independent frequency configurability at both ends [11-13]. The frequency reconfigurable antenna is designed for the multiple band applications [14-18]. The concentric circular ring antenna is designed to shift the ISM band application frequencies given in [19-24]. The $\mathrm{u}-$ shaped antenna is designed to shift to get the frequency reconfigurable properties [25-28].
The concentric rings shaped antenna is designed for triple band applications for various wireless application. The arc shaped slots are inserted in the to improve the S11 of the antenna. The antenna operates in the frequency ranges from 2.2-3.6 GHZ 4.2-4.6 GHz and third 5.2-5.7 GHz. In the section 2 provides the antenna design part, in the section 3 provides the result and discussion of the antenna finally section 4 provides the reconfigurability of the antenna.

\section{Antenna design}

Fig. 1 represents the basic antenna iterations to achieve the proposed antenna design. The basic antenna consists of the circular ring with radius of Rc1 and Rc2.To create the concentric ring inside the antenna structure the ring is inserted with the radius of Rc3 and Rc4. Similarly, to create the third concentric ring inside the second ring the radius of Rc4 and Rc5 is taken. Similarly, to create the fourth smaller circle the circle radius of Rc6 is considered. The FR4 substrate is used for designing the antenna with the dimensions of $45 \times 25 \times 1.6 \mathrm{~mm} 3$. To design the proposed antenna CPW feeding is used. The design of the proposed antenna is done in the commercially available software High Frequency Structural Simulator (HFSS), a full wave EM software capable of simulating a finite element method. the antenna structure was printed on a FR4 substrate with dielectric constant of 4.4 and loss tangent of 0.016 . The parametric investigation is done for the proposed antenna designer which can understand antenna characteristics. Fig. 2 represents the dimensions of proposed antenna.

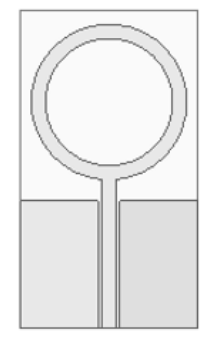

(a)

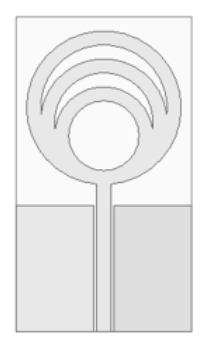

(c)

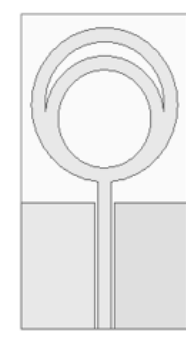

(b)

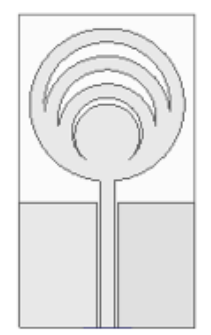

(d)
Figure. 1 Iteration steps of antenna: (a) Ant-1, (b) Ant-2, (c) Ant-3, and (d) Ant-4 


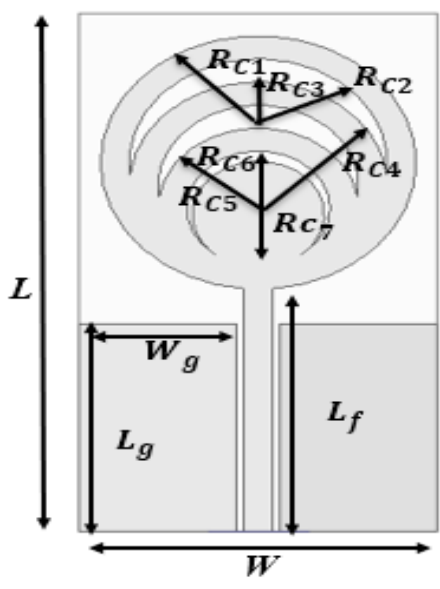

(a)

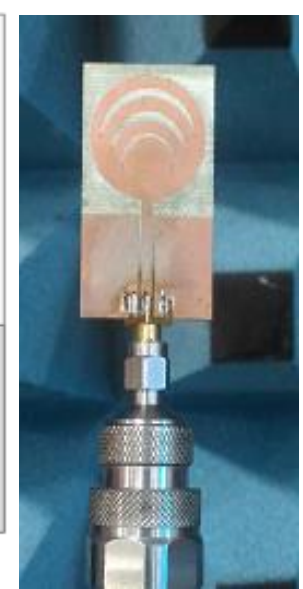

(b)
Figure. 2 (a) proposed antenna design and (b) fabricated antenna

Table 1. Dimensions of proposed antenna

\begin{tabular}{|c|c|c|c|}
\hline Parameter & Value $(\mathrm{mm})$ & Parameter & Value $(\mathrm{mm})$ \\
\hline $\mathrm{L}$ & 45 & $R c_{1}$ & 11 \\
\hline $\mathrm{W}$ & 25 & $R c_{2}$ & 9 \\
\hline$L_{g}$ & 18 & $R c_{3}$ & 8 \\
\hline$W_{g}$ & 11 & $R c_{4}$ & 7.5 \\
\hline$L_{f}$ & 21 & $R c_{5}$ & 7 \\
\hline$w_{f}$ & 2 & $R c_{6}$ & 5 \\
\hline $\mathrm{a}$ & 0.5 & $R c_{7}$ & 4.6 \\
\hline
\end{tabular}

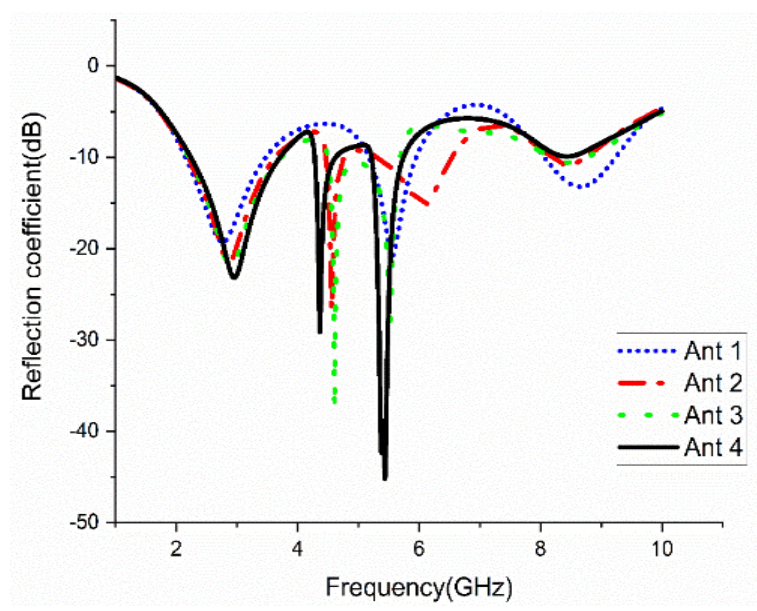

Figure. 3 Reflection coefficients of antenna iterations

\section{Results and discussions}

Fig. 3 represents the reflection coefficient of antenna iterations. The basic single ring antennal resonates at dual frequency ranging from at first band is $2.2-3.45 \mathrm{GHz}$ with $\mathrm{S} 11$ of $-19 \mathrm{~dB}$ at $2.7 \mathrm{GHz}$ and second band ranging from 5.2-5.9 GHz with $\mathrm{S} 11$ of $-20 \mathrm{~dB}$ at $5.5 \mathrm{GHz}$. When the second ring is inserted in the first ring the reflection coefficient of antenna changed and operates at $2.2-3.6 \mathrm{GHz}$ with $\mathrm{S} 11$ of $-21 \mathrm{~dB}$ at $2.9 \mathrm{GHz}$, second band at $4.5-4.7 \mathrm{GHz}$

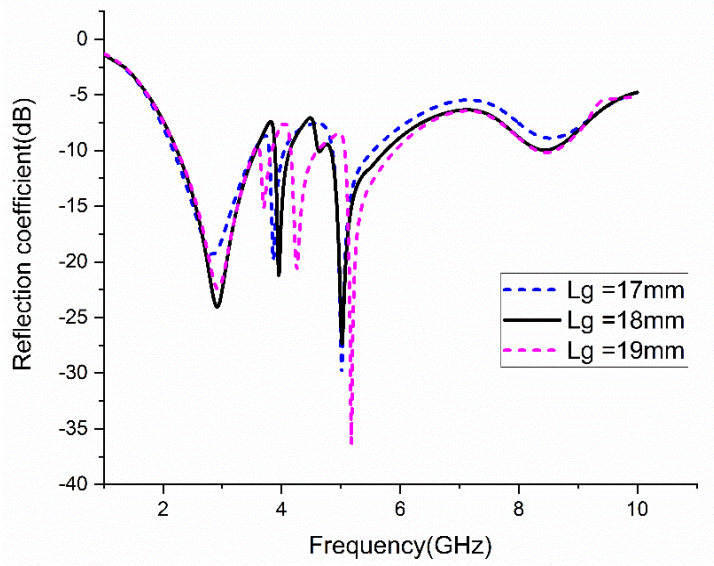

Figure. 4 Parametric analysis for length of the ground

with $\mathrm{S} 11$ of $-26 \mathrm{Db}$ at $4.55 \mathrm{GHz}$ and small operating band ranging from $5.36-6.5 \mathrm{GHz}$ with $\mathrm{S} 11$ of $-14 \mathrm{~dB}$ at $6.0 \mathrm{GHz}$. Similarly, when the third ring is added in the antenna operates in the frequencies like 2.2-3.7 $\mathrm{GHz}$ with $\mathrm{S} 11$ of $-22 \mathrm{~dB}$ at $2.9 \mathrm{GHz}$ and $4.5-5.6 \mathrm{GHz}$ with $\mathrm{S} 11$ of $-36 \mathrm{~dB}$ at $4.6 \mathrm{GHz}$.Finally the proposed antenna shows triple band.

\subsection{Parametric study}

Fig. 4 illustrates the reflection coefficient for different values of the ground plane (L1). The value of L1 is varied from 17 to $19 \mathrm{~mm}$ in all the WLAN/WiMAX bands. It should be noted that the ground plane dimensions can affect the impedance matching and resonant frequency of three operating bands. For the different values of the L1 antenna resonates at the triple band characteristics which covers the frequency ranges 2.2-3.5,3.8-3.7, 4.6-5.5 $\mathrm{GHz}$ which cover many wireless application frequency bands WLAN ISM Bluetooth and WiMAX applications. It is observed that the as the value of L1 increases the shift in the frequency is observed in the right side.

Fig. 5 illustrates the reflection coefficient by changing the different values of radius of the circle1.The value of circle 1 is varied from $9 \mathrm{~mm}$ to $11 \mathrm{~mm}$ with the step size of $1 \mathrm{~mm}$. The reflection coefficient of the antenna shows the triple band characteristics of the antenna.

To design a good triple band WLAN/WiMAX operation, Rc1 is set at $11 \mathrm{~mm}$.similarly, Fig 6 illustrates the return loss for the different values radius of the circle $7(\mathrm{Rc} 7)$. It can be seen in figure that the impedance band width and characteristics of the reflection coefficient to be changed if the Rc7 is changed from 2.5 to $4 \mathrm{~mm}$. The effect of the finial circle radius is very less when it is compared to the first circle radius. The small variation of the $\mathrm{S} 11$ is observed in the plots. For designing of best triple 
band WLAN/WiMAX operation, Rc7 selected to be $3.5 \mathrm{~mm}$ because it shows the better $\mathrm{S} 11$ results compared to other parameters.

\subsection{Current distributions}

To verify the performance of the proposed antenna reflection and radiation characteristics. To recognize the creation of notch bands the current distributions on the surface of the proposed antenna at 2.8, 4.5, and 5.4 are shown Fig. 5. In Fig. 5(a) it is observed that the surface current are flows around the feed line and ground when the proposed antenna operates at $2.8 \mathrm{GHz}$. the most of the current distributed along the feed line and the edges of the concentric circular rings. Furthermore, the current flows at feed line, ground and some part of the patch, it is shown in fig 5(b). That the current flows are relatively concentrated on the feed line when the proposed antenna operates at $4.5 \mathrm{GHz}$. As shown in fig5(c) the current flows in feed line and some part of patch when the proposed antenna operates at $5.4 \mathrm{GHz}$.

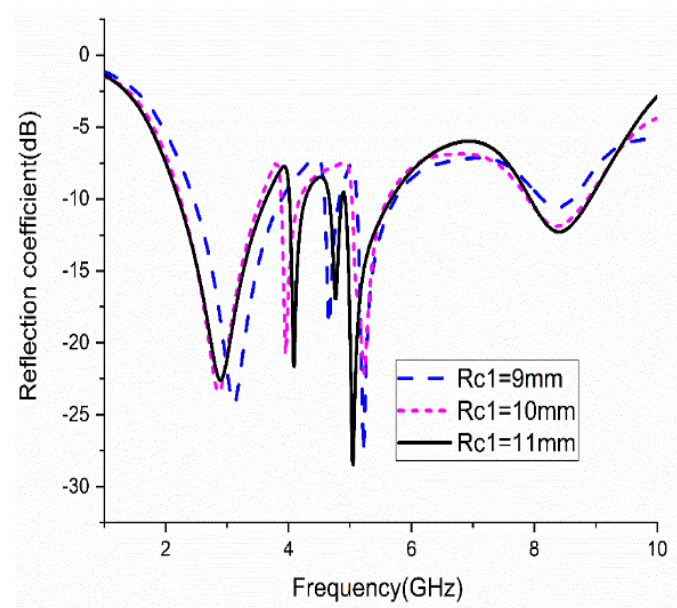

Figure. 5 Parametric for varying first circle radius

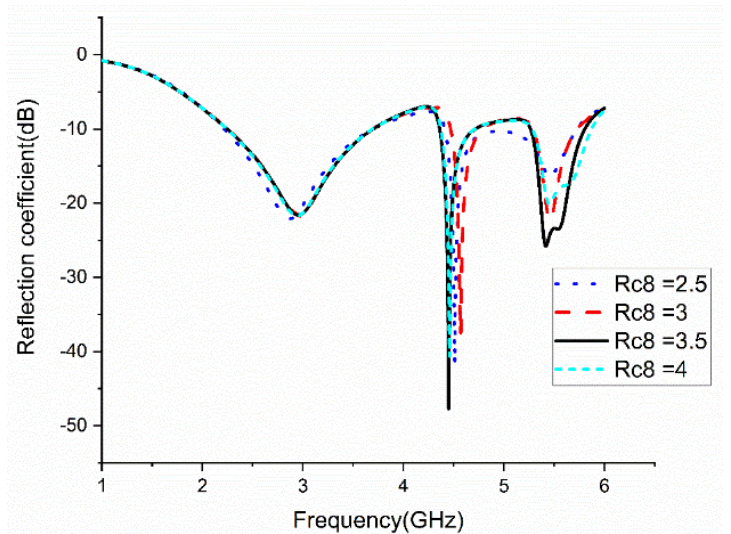

Figure. 6 Parametric analysis for varying the last circle radius

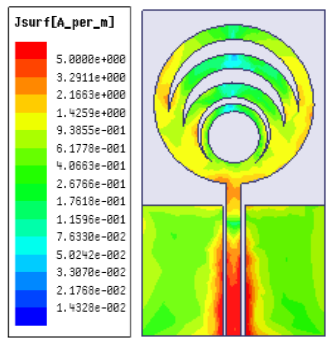

(a)

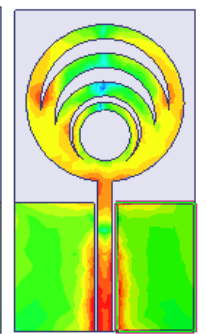

(b)

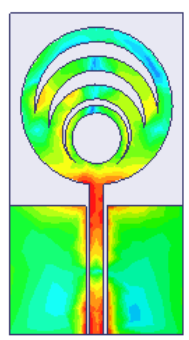

(c)
Figure. 7 simulated current distributions on the radiating patch: (a) $2.8 \mathrm{GHz}$, (b) $4.5 \mathrm{GHz}$, and (c) $5.4 \mathrm{GHz}$

\subsection{Radiation pattern}

The radiation patterns of the proposed antenna are illustrated in Fig. 8. Among various methods that are available to represent the radiation patterns in this paper uses the XY-plane, YZ-plane and ZXplane approach. In Fig. 6 (a) the pattern in XY-plane for different frequencies such as $2.8 \mathrm{GHz}, 4.5 \mathrm{GHz}$, and $5.4 \mathrm{GHz}$ are shown. It is seen that the radiation patterns of the designed antenna are bidirectional in XY-plane. In Fig. 6 (b) the pattern in ZX-plane for different frequencies such as $2.8 \mathrm{GHz}, 4.5 \mathrm{GHz}$, and $5.4 \mathrm{GHz}$ are shown. It is seen that the radiation patterns of the designed antenna are omnidirectional in ZX-plane. In Fig. 6 (c) the pattern in YZ-plane for different frequencies such as $2.8 \mathrm{GHz}, 4.5 \mathrm{GHz}$, and $5.4 \mathrm{GHz}$, are shown.it is seen that the radiation patterns of the designed antenna are bidirectional in this YZ-plane.

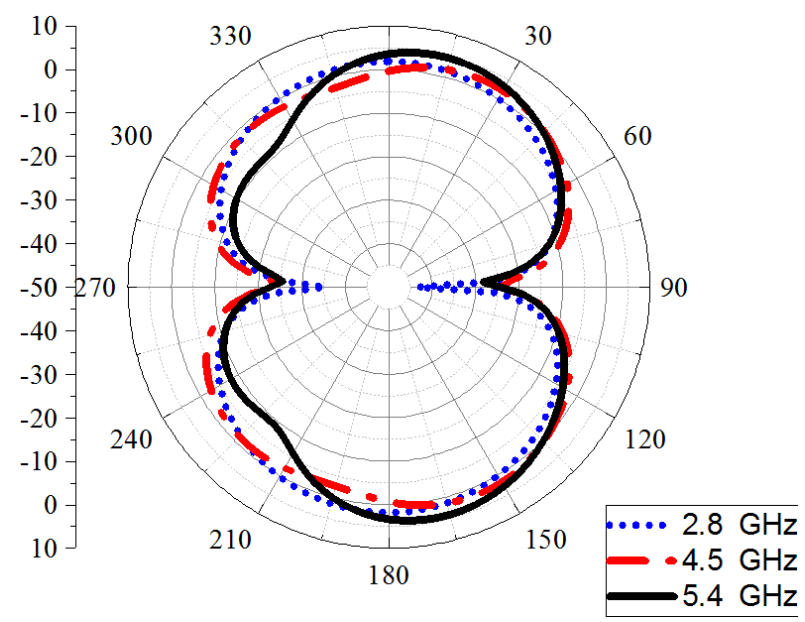

(a) 


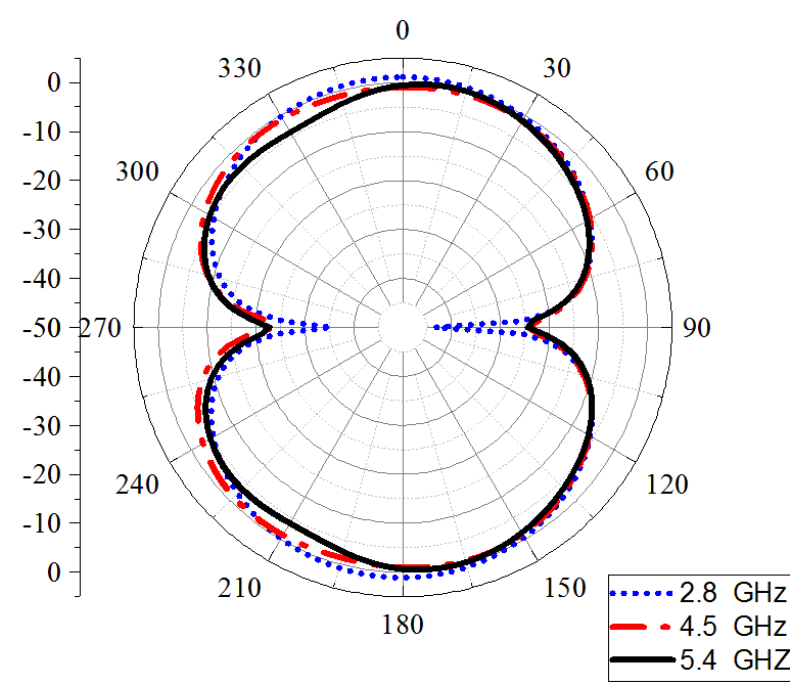

(b)

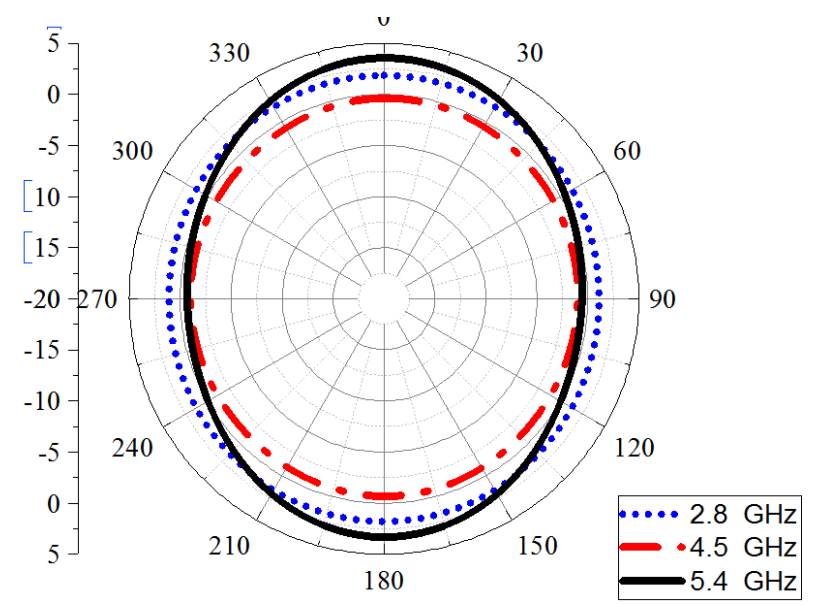

(c)

Figure. 8 Radiation patterns of the proposed antenna: (a) XY-plane, (b) XZ-plane, and (c) YZ-plane

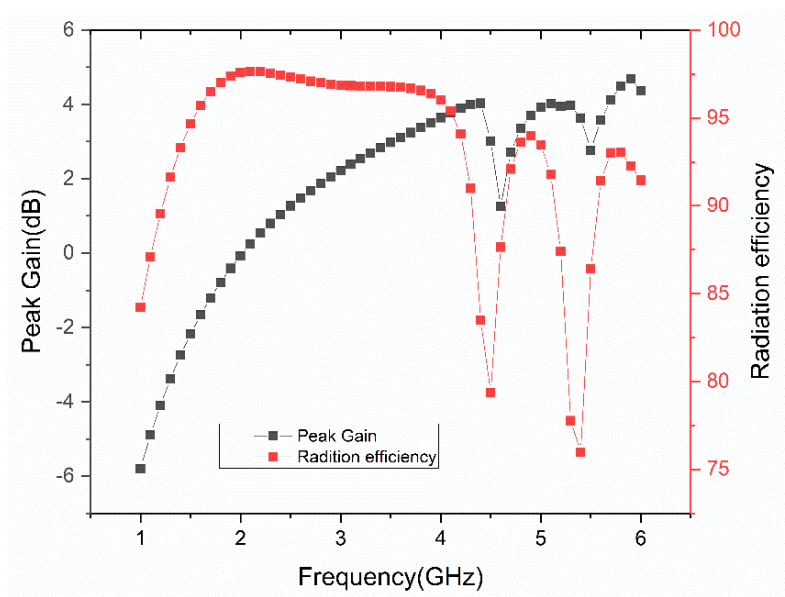

Figure. 9 Peak gain and radiation efficiency of the antenna

\subsection{Peak gain and radiation efficiency}

The peak gain and the radiation efficiency are observed at the three resonating frequencies. The

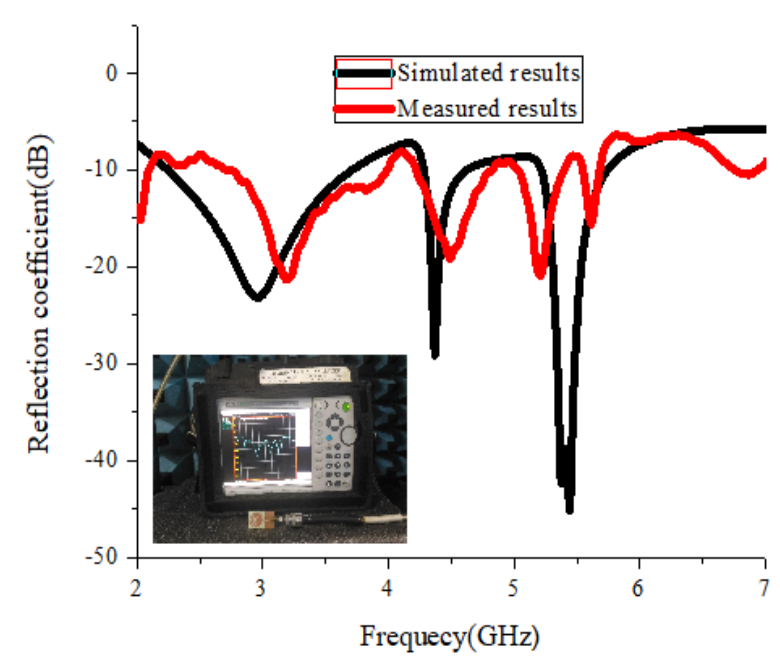

Figure. 10 Simulated and measured reflection coefficient of proposed antenna

antenna provides the peak gain of $2.05 \mathrm{dBi}$ at 2.9 $\mathrm{GHz}, 3.9 \mathrm{dBi}$ at $4.3 \mathrm{GHz}$ and $3.5 \mathrm{dBi}$ at $5.4 \mathrm{GHz}$ at three resonating frequency. The radiation efficiency at the three resonating bands is $96 \%$ at 2.05 $\mathrm{GHz}, 93 \%$ at $4.3 \mathrm{GHz}$ and $86 \%$ at $5.4 \mathrm{GHz}$.

The comparison of simulated and measured results of the proposed antenna show in fig. 10 and shows triple band frequency application with slight variation in the resonating frequency is observed in Vector Network Analyzer

\section{Reconfigurability}

To study the reconfigurable nature of the antenna three pin diodes of BAR-64-02 V are placed in between the concentric circular and their performance is evaluated. Fig. 11 represents the exact location of the pin diodes on the antenna. By placing the three diodes overall 8 conditions are studied out of this condition only few switches provide the frequency shift in the frequency.

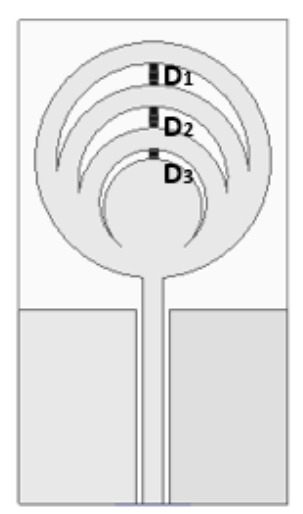

Figure. 11 Diodes placement on the antenna 


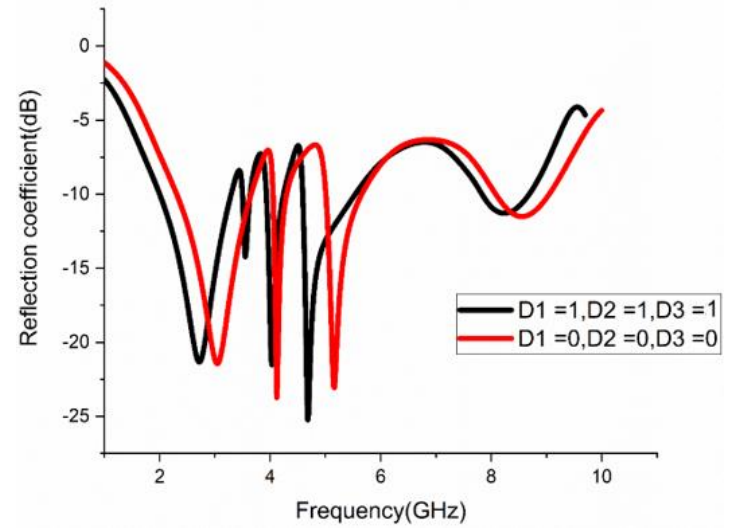

Figure. $12 \mathrm{ON}$ and $\mathrm{OFF}$ switching conditions on the antenna

In all switches ON condition antenna resonates at frequency $2.72 \mathrm{GHz}$ and operates with frequency range of $2-3.29 \mathrm{GHz}$ with $\mathrm{S}_{11}$ is $-21.32 \mathrm{~dB}$, and in second resonating frequency of $3.59 \mathrm{GHz}$ and operates in the frequency range of $3.5-3.63 \mathrm{GHz}$ with $\mathrm{S}_{11}$ is $-12.59 \mathrm{~dB}$, and third resonating frequency of $4.03 \mathrm{GHz}$ and covers the frequency range of 3.94$4.24 \mathrm{GHz}$ with $\mathrm{S}_{11}$ is $-21.51 \mathrm{~dB}$, and fourth resonant frequency $4.68 \mathrm{GHz}$ and covers the frequency range of in $4.59-5.53 \mathrm{GHz}$ with $\mathrm{S}_{11}$ is $-25.22 \mathrm{~dB}$. Similarly when all the switches are in OFF condition it first resonant frequency of $3.04 \mathrm{GHz}$ and operates in the frequency range of $2.31-3.65 \mathrm{GHz}$ with $\mathrm{S}_{11}$ is $21.43 \mathrm{~dB}$, and second resonant frequency of $4.12 \mathrm{GHz}$ and covers the frequency range of 4.06$4.29 \mathrm{GHz}$ with $\mathrm{S}_{11}$ is $-23.72 \mathrm{~dB}$, and the third resonant frequency is $5.16 \mathrm{GHz}$ and covers the frequencies of $5.01-5.65 \mathrm{GHz}$ with $\mathrm{S}_{11}$ is $23.06 \mathrm{~dB}$, and finally it is having the resonating frequency $8.55 \mathrm{GHz}$ at this it is operated in between range of $8.09-9 \mathrm{GHz}$ with $S_{11}$ is $-11.50 \mathrm{~dB}$.

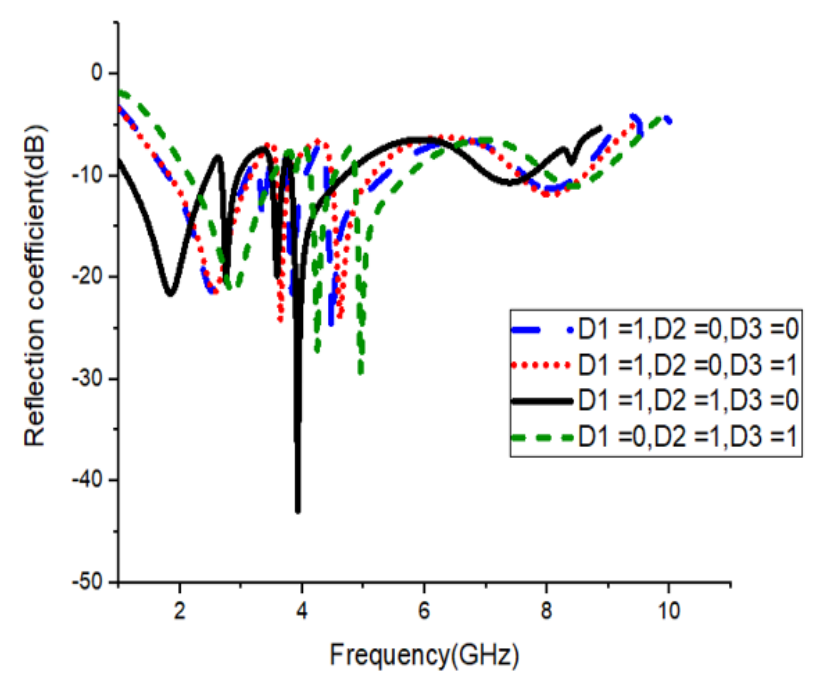

Figure. 13 Antenna performance for different switching condition
Fig. 13 shows the switching conditions of the antenna. When the diodes are (1) ON, OFF, OFF (2) ON, OFF, ON (3) ON, ON, OFF (4) OFF, ON, OFF. Where $\mathrm{D} 1=1$ shows the $\mathrm{ON}$ and $\mathrm{D} 2=0$ shows the OFF modes.

\section{$D_{1}=O N, D_{2}=O F F, D_{3}=O F F$.}

In this condition it is having the resonant frequency $2.52 \mathrm{GHz}$ at this frequency it is operated between the $1.8-3.09 \mathrm{GHz}$ with $\mathrm{S}_{11}$ is $-21.32 \mathrm{~dB}$, at $3.35 \mathrm{GHz}$ it is operated $3.3-3.47 \mathrm{GHz}$ with [S11] is $-14.22 \mathrm{~dB}$, and in the frequency range $3.83 \mathrm{GHz}$ it is having operating frequency $3.74-4.04 \mathrm{GHz}$ with $S_{11}$ is $-21.51 \mathrm{~dB}$, and resonant frequency is $4.48 \mathrm{GHz}$ it is operated at 4.39 $5.33 \mathrm{GHz}$ with $\mathrm{S}_{11}$ of $-25.22 \mathrm{~dB}$, and finally at the range of $8.04 \mathrm{GHz}$ it is operated at $7.64-8.48 \mathrm{GHz}$ with $S_{11}$ is $-11.28 \mathrm{~dB}$.

\section{$D_{1}=\mathrm{ON}, \mathrm{D}_{2}=\mathrm{OFF}, \mathrm{D}_{3}=\mathrm{ON}$.}

In this condition it is having the resonant frequency $2.56 \mathrm{GHz}$ it is operated at $1.83-3.14 \mathrm{GHz}$ with the $\mathrm{S}_{11}$ is $-21.48 \mathrm{~dB}$, and at $3.64 \mathrm{GHz}$ it having operating frequency $3.58-3.8$ with $\mathrm{S}_{11}$ is $-24.23 \mathrm{~dB}$, next it is having resonant frequency of $4.62 \mathrm{GHz}$ with frequency range of $4.48-5.12$ with $S_{11}$ is $-24.04 \mathrm{~dB}$, and finally it is having the $8.06 \mathrm{GHz}$ resonant frequency it is operated at $7.55-8.59 \mathrm{GHz}$ with $\mathrm{S}_{11}$ is $-11.82 \mathrm{~dB}$.

\section{$D_{1}=O N, D_{2}=O N, D 3=O F F$.}

In this condition it is having the resonant frequency $1.84 \mathrm{GHz}$ with frequency range of $1.13-2.45 \mathrm{GHz}$ with $S_{11}$ is $-21.59 \mathrm{~dB}$, second resonating frequency of $2.75 \mathrm{GHz}$ it is operated at $2.68-2.94 \mathrm{GHz}$ with $\mathrm{S}_{11}$ is $20.48 \mathrm{~dB}$, and third resonating frequency of $3.58 \mathrm{GHz}$ with frequency range of $3.5-3.68 \mathrm{GHz}$ with $\mathrm{S}_{11}$ is $19.83 \mathrm{~dB}$, and finally at the $3.92 \mathrm{GHz}$ with operating frequency range of $3.82-4.69 \mathrm{GHz}$ with $\mathrm{S}_{11}$ is $42.90 \mathrm{~dB}$.

\section{$D_{1}=\mathrm{OFF}, \mathrm{D}_{2}=\mathrm{ON}, \mathrm{D}_{3}=\mathrm{ON}$.}

In this condition it is having resonant frequency $2.87 \mathrm{GHz}$ at this frequency it is operated in the range of $2.15-3.51 \mathrm{GHz}$ with $\mathrm{S}_{11}$ is $-21.49 \mathrm{~dB}$, and next it is having the $4.24 \mathrm{GHz}$ resonant frequency at this it is operated in $4.14-4.51 \mathrm{GHZ}$ with $\mathrm{S}_{11}$ is $-27.10 \mathrm{~dB}$, and in next cycle it is having frequency $4.95 \mathrm{GHz}$ at this frequency it is operated in $4.87-5.71 \mathrm{GHz}$ with $S_{11}$ is $-29.22 \mathrm{~dB}$, and finally it is having the frequency $8.41 \mathrm{GHz}$ at this frequency it is operated in 8.04 $8.8 \mathrm{GHz}$ with $\mathrm{S}_{11}$ is $-11.03 \mathrm{~dB}$. 
Table 2. Comparison of previous literature

\begin{tabular}{|c|c|c|c|c|c|c|}
\hline Reference & $\begin{array}{c}\text { Antenna } \\
\text { Size }\left(\mathrm{mm}^{3}\right)\end{array}$ & $\begin{array}{c}\text { Operating } \\
\text { bands } \\
(\mathrm{GHz})\end{array}$ & $\begin{array}{c}\text { Impedance } \\
\text { Bandwidth } \\
(\%)\end{array}$ & $\begin{array}{c}\text { Gain } \\
(\mathrm{dBi})\end{array}$ & Diodes & $\begin{array}{c}\text { Reconfigurable } \\
\text { Technique }\end{array}$ \\
\hline$[1]$ & $40 \times 20 \times 1$ & $\begin{array}{c}1.9-3.1 \\
3.4-4.1\end{array}$ & $\begin{array}{c}48.3 \\
19.8\end{array}$ & $\begin{array}{c}3.5 \\
1.5\end{array}$ & - & - \\
& & $5.1-6$ & 15.2 & 0.8 & & \\
\hline$[2]$ & $38 \times 32 \times 1.6$ & $3.05-13$ & 123 & 5.4 & 2 & Stubs and slots \\
\hline$[8]$ & $40 \times 40 \times 1.6$ & $2.25-4.04$ & 57 & 1.56 & 2 & U-shaped slot \\
\hline$[13]$ & $52 \times 52 \times 1.6$ & $2.4-2.8$ & 15 & 4.68 & 3 & Stubs \\
\hline$[14]$ & $50 \times 45 \times 1.6$ & $2-5.8$ & 97 & 5.14 & 2 & Stubs \\
\hline Proposed & $45 \times 25 \times 1.6$ & $2.2-3.6$ & 48 & 2.9 & 3 & Added Rings \\
Work & & $4.3-4.6$ & 9 & 3.9 & & \\
& & $5.2-5.7$ & 10 & 3.4 & & \\
\hline
\end{tabular}

The comparison of previous literature is done in the Tabl.2. the size of the antenna is compact and provides triple band frequency applications and uses the 3-BAR-64-02v Pin diodes to switch 8 different states.

\section{Conclusion}

In these a modified concentric circular ring antenna which is having the three circular rings with CPW fed antenna was proposed for WLAN/WiMAX applications. The antenna provides the triple band nature and resonates at the frequencies like $2.9 \mathrm{GHz}, 4.3 \mathrm{GHz}$ and $5.4 \mathrm{GHz}$. The radiation patterns are in omnidirectional and bidirectional at their operating bands. In addition, the proposed antenna is having the good characteristics in operating bands it is very useful for wireless communication systems in multi band applications. In all the three switches are in ON condition the antenna resonates at $2.72 \mathrm{GHz}$ when the switches are in OFF it shifted to $3.04 \mathrm{GHz}$ with shift frequency of $0.32 \mathrm{GHz}$. Similarly the second and third frequencies frequency shift of $0.53 \mathrm{GHz}$ and $0.48 \mathrm{GHz}$ shift of frequency is observed.

\section{Acknowledgments}

The authors express gratitude to Department of Science and Technology through EEQ/2016/000604 and ECR/2016/000569 for their support.

\section{References}

[1] J. H. Yoon and Y. C. Rhee, "A modified threecircular-ring monopole antenna for WLAN/WiMAX triple-band operations", In: Microwave Conference Proceedings, AsiaPacific, pp. 1142-1144, 2013,

[2] M. S. Alam and A. Abbosh, "Reconfigurable band-rejection antenna for ultra-wideband applications", IET Microwaves, Antennas \& Propagation, Vol.12, No.2, pp.195-202, 2017.

[3] A. K. Singh, R. K. Gangwar, and B. K. Kanaujia, "Sectored annular ring microstrip antenna with DGS for circular polarization", Microwave and Optical Technology Letters, Vol.58, No.3, pp.569-573, 2016.

[4] R. Kumar and P. N. Choubey, "Design of pentagonal circular fractal antenna with and without notched-band characteristics", Microwave and Optical Technology Letters, Vol.55, No.2, pp.430-434, 2013.

[5] D. J. Kim, J. H. Choi, and Y. S. Kim, "CPW-Fed Ultrawideband Flower-Shaped Circular Fractal Antenna", Microwave and Optical Technology Letters, Vol.55, No.8, pp.1792-1795, 2013.

[6] M. Nosrati and N. Tavassolian, "Miniaturized circularly polarized square slot antenna with enhanced axial-ratio bandwidth using an antipodal Y-strip", IEEE Antennas and Wireless Propagation Letters, Vol.16, pp.817820, 2017.

[7] B. Majumdar and K. P. Esselle, "A dual-mode reconfigurable patch antenna and an extended transmission line model", Microwave and Optical Technology Letters, Vol.58, No.1, pp.57-61, 2016.

[8] S. Shi, W. Ding, and K. Luo, "Dual-band reconfigurable circularly polarized monopole antenna", International Journal of $R F$ and Microwave Computer-Aided Engineering, Vol.25, No.2, pp.109-114, 2015.

[9] Y. Zhao, K. Wei, Z. Zhang, and Z. Feng, "A bidirectional waveguide antenna with polarization reconfigurable capability", Microwave and Optical Technology Letters, Vol.56, No.2, pp.422-427, 2014.

[10] N. Nguyen-Trong, L. Hall, and C. Fumeaux, "A dual-band dual-pattern 
frequency-reconfigurable antenna", Microwave and Optical Technology Letters, Vol.59, No.11, pp.2710-2715, 2017.

[11] P. Pardhasaradi, B.T.P. Madhav, G.K. Sai, M. Venkateswararao, B. Ganesh, N. Tarakaram, and D.P. Teja, "Metamaterial Inspired Reconfigurable Fractal Monopole Antenna for Multiband Applications", International Journal of Intelligent Engineering and Systems, Vol.12, No.2, pp. 53-61, 2019.

[12] B.T.P. Madhav and M. P. Kishore, "Bandwidth Enhancement of CPW-Fed Elliptical Curved Antenna with Square SRR", International Journal of Intelligent Engineering and Systems, Vol.11, No.2, pp. 68-75, 2018.

[13] M. Kosuru, K. Umakantham, and K. Satyanarayana, "Reconfigurable Notch Band Monopole Slot Antenna for WLAN/IEEE802.11n Applications", International Journal of Intelligent Engineering and Systems, Vol.10, No.6, pp. 166-173, 2017.

[14] M.V. Lakshmi, P. Pardhasaradhi, B.T.P. Madhav, "A Coplanar Waveguide Fed Asymmetric Ground Frequency Reconfigurable Antenna", International Journal of Intelligent Engineering and Systems, Vol.11, No.4, pp 293-300, 2018.

[15] U. Devi, M.S.S. Rukmini, and B.T.P. Madhav, "A Compact Conformal Printed Dipole Antenna for 5G Based Vehicular Communication Applications", Progress in Electromagnetics Research C, Vol. 85, pp 191208, 2018.

[16] M.S.S.S Srinivas, and T.V. Ramakrishna, "Wideband defected Ground Structured Monopole Antenna with Electromagnetic Band Gap Loading”, Journal of Engineering and Applied Sciences, Vol. 13, No. 11, pp 40994103, 2018.

[17] B.T.P. Madhav, S. Rajiya, B.P. Nadh, and M.S. Kumar, "Frequency reconfigurable monopole antenna with DGS for ISM band applications", Journal of Electrical Engineering, Vol. 69, No. 4, pp 293-299, 2018.

[18] B.T.P. Madhav, G.S. Dheeraj, and S.S. Raghavarapu, "Multiple Band Mobile Antenna for LTE, GSM, PCS, UMTS \& IoT Applications", International Journal of Engineering \& Technology, Vol 7, No 3.27, pp 609-612,2018

[19] R. Aradhyula, T.V.R. Krishna, B.T.P. Madhav, "Electromagnetic Bandgap Structured CPW Fed Circular Monopole Antenna with Bandwidth Enhancement for Wideband Applications", International Journal of
Engineering \& Technology, Vol.7, No.3, pp 617-620,2018.

[20] K.S.R. Murthy, K. Umakantham, K.S.N Murthy, and B.T.P. Madhav, "Polarization and Frequency Reconfigurable Antenna for Dual Band ISM Medical and Wi-Fi Applications", International Journal of Engineering \& Technology, Vol.7, No .3, pp 651-654, 2018.

[21] B.T.P. Madhav, G.S. Dheeraj, and S.S. Raghavarapu, "Design of a CPW-Fed Monopole Antenna for Ultrawide Band based IoT and Medical Applications", International Journal of Pharmaceutical Research, Vol.10, No. 4, pp. 74-79, 2018.

[22] U. Devi and M.S.S. Rukmini, "Liquid crystal polymer based flexible and conformal 5G antenna for vehicular communication", Materials Research Express, Vol.6, No.1, pp 112, 2019.

[23] M.S. Kumar, M.V. Rao, and T. Anilkumar, "Circular ring structured ultra-wideband antenna for wearable applications", International Journal of $R F$ and Microwave Computer-Aided Engineering, Vol. 28, No. 9, pp. 1-15, 2018.

[24] M. Venkateswara Rao, B.T.P. Madhav, T. Anil Kumar, B. Prudhvi Nadh, "Metamaterial inspired quad band circularly polarized antenna for WLAN/ISM/Bluetooth/WiMAX and satellite communication applications", $A E U$ International Journal of Electronics and Communications, Vol. 97, pp. 229-241, 2018.

[25] U. Devi and T.A. Kumar, "Defected ground structured compact MIMO antenna with low mutual coupling for automotive communications", Microwave and Optical Technology Letters, Vol. 61, No. 3, pp. 794-800, 2019.

[26] M.S. Kumar, M.V. Rao, and T. Anilkumar, "Asymmetric Ground Structured Circularly Polarized Antenna for ISM and WLAN Band Applications", Progress in Electromagnetics Research M, Vol. 76, pp. 167-175, 2018.

[27] G.J. Devi, P. Lakshman, and T. Anilkumar, "A CPW-fed Sigma-shaped MIMO Antenna for Ka Band and 5G Communication Applications", Journal of Telecommunications and Information Technology, Vol. 21, No. 4, pp. 1-8, 2018.

[28] M.V. Lakshmi and P. Pardhasaradhi "Circular Monopole Reconfigurable Antenna with Notch Band Filter Characteristics", Journal of Engineering Science and Technology Review, Vol .11, No.5, pp 139-143, 2018. 